\title{
Self-Esteem and Reactive Aggression: An EMG Biofeedback Training Approach
}

\author{
Sukhminder Kaur ${ }^{1}$, Sandeep Kaur ${ }^{2}$ \\ ${ }^{1}$ Department of Psychology, Punjabi University, Patiala, Punjab, India \\ ${ }^{2}$ Cambie Counselling Services, Richmond, British Columbia, Canada
}

Email address:

sukhminder_bhattal@yahoo.co.in (Sukhminder K.), sandeepsidhuu@gmail.com (Sandeep K.)

\section{To cite this article:}

Sukhminder Kaur, Sandeep Kaur. Self-Esteem and Reactive Aggression: An EMG Biofeedback Training Approach. American Journal of Applied Psychology. Vol. 10, No. 2, 2021, pp. 49-54. doi: 10.11648/j.ajap.20211002.13

Received: April 15, 2021; Accepted: May 10, 2021; Published: May 20, 2021

\begin{abstract}
Human aggression and violence is a worldwide public health concern that has greater influence on both the offenders and victims. Although many theorists have recognized multiple and complex causes of such behaviors, a number of researchers have pointed out self-esteem as an important component in behavioral change and prevention of crime. The association of self-esteem and aggression is most frequently studied and traditional viewpoint assumes that low self-esteem is a significant predictor of aggression. Researchers suggest that individuals with low self-esteem may benefit from therapeutic techniques. Following indications from the previous researches, the objective of the present study was to examine the role of EMG biofeedback in enhancing self-esteem of aggressive adolescents. It was hypothesized that EMG biofeedback would improve self-esteem and reduce reactive aggression of participants in experimental group. A pre-post experimental-control group design was used. Self-Esteem Inventory and Reactive-Proactive Aggression Questionnaire were used to identify male adolescents with low self-esteem and high reactive aggression respectively. Further identified subjects were randomly assigned to experimental and control groups. EMG biofeedback training was given to participants of experimental group ( $\mathrm{n}=90)$ for ten sessions. Control group $(\mathrm{n}=90)$ participants did not receive any training. At the completion of intervention program, participants of both groups were again assessed on Reactive-Proactive Aggression Questionnaire and Self-Esteem Inventory. Obtained scores were subjected to one way Analysis of Variance. It was revealed that EMG biofeedback training made a significant improvement in students' level of self-esteem ( $\mathrm{F}=57.88, \mathrm{p}<0.01)$ and a significant reduction in reactive aggression $(\mathrm{F}=121.31, \mathrm{p}<0.01)$ among participants of experimental group. The significant implications of the findings have been discussed.
\end{abstract}

Keywords: Aggression, Self-esteem, Biofeedback Training

\section{Introduction}

The present day scenario witnesses the rising incidents of destructive and antisocial behavior among adolescents that has drawn the attention of psychologists, sociologists and counselors to name a few. These incidents include a wide variety of aberrations such as cruelty, vandalism, violence and even extreme forms of school shootings and stabbings. The development of these behaviors in adolescence is often considered as a consequence of factors such as inbuilt temperament (hyperactivity, impulsivity), poor problem solving skills, harsh and uninvolved parenting and couples with indiscriminate exposure to media violence. From the standpoint of finding the root cause of such behaviors, research literature directly holds reactive aggression as the major culprit. This form of aggression has been characterized by responding aggressively to defend the self against perceived threats for instance physical attacks and verbal behavior that causes psychological harm to other people [1]. It is an action oriented aggression in which a person expresses his/her negative emotions in a reactive manner like hitting, kicking and punching. Children with aggressive tendencies are more likely to display antisocial behaviors relatively poor psychosocial health and a greater number of adjustment problems as compared to well-adjusted peers [2]. Thus, the need of hour is to control the problem of aggression in adolescents in order to prevent more severe problems and evoke better performance. A number of theories have explained the causes of aggressive behavior and concluded 
that aggression is the outcome of individual and situation related factors. One of the individual factor that has been considered as a significant component in the occurrence of aggressive behavior is self-esteem.

\subsection{Self-esteem and Aggression}

Self-esteem is the foundation of healthy psychological functioning in human life. During adolescence period, there is an increased focus on internal world of thoughts and feelings as well as outer world of relationships [3,4]. This is the time when adolescents evaluate themselves and make social comparisons. They attempt to establish their identity and their place in the social hierarchy. Researchers suggest that people with high self-esteem evaluate themselves as worthy and competent. They are more confident for their future goals. It plays an important role in general health and wellness of people. Low self-esteem on the other hand can be quite detrimental to well-being and even the very existence of the individual. It creates anxiety, stress, loneliness and depression [5], binge eating [6] and can generate and increased vulnerability to drug abuse and externalizing problems like delinquency and aggression [7] as well as suicidal ideation [8]. In this regard, it was suggested that aggression may provide an increased sense of power and independence to people with low-esteem [9]. With outward expression, these people protect themselves against feelings of inadequacy and inferiority as well as seek attention from others. The association of aggression with self-esteem among adolescents is currently a topic of debate among many researchers [10]. There is a controversial link between global self-esteem and externalizing problems such as aggression, antisocial behavior and delinquency [11]. Most of the researches based on 'threatened egotism model' or 'disputed self-esteem hypothesis' indicate that individuals with unrealistic high self-esteem have a tendency to be aggressive or violent $[12,13]$. Similarly, low self-esteem has been regarded as a significant predictor of aggression within the framework of traditional viewpoint. Individuals with low self-esteem perceive themselves as bad people who cry and act out of anger. Due to anger and hostility, they are prone to reactive aggression [14]. Researches in this context have stated that people who react aggressively have low self-esteem because they might not have inner resources to cope with frustrations in life $[15,16]$. Such individuals with inaccurate perceptions may get benefit from therapeutic techniques that help them to see themselves as more competent than they believe. Hence, in the present research work an attempt was made to modify self-esteem of male adolescents which in turn reduce their aggressive behavior.

\subsection{Biofeedback Training: An Intervention}

Biofeedback, as the term implies, gives information to the person about his/her physiological activities through the instruments. It is a self-regulatory technique that enables an individual to learn how to change physiological activity for the purpose of improving, physiological, mental and emotional health as well as performance in varied areas of life. Studies have shown that biofeedback training as a relaxation technique change thinking, emotions and behaviors of users. Over the time, these changes are stabilized [17]. Because during training period, a user learns to recognize the relationship between mind and bodily changes and with this insight he comes to exert more control over his bodily responses. Biofeedback is a process that provides real time information from psycho physiological recordings about the level at which physiological systems are functioning [18]. It operates on the notion that we have an innate ability and potential to influence the automatic functions of our bodies through the exertion of will and mind. In this regard, previous researches revealed that biofeedback techniques train individuals to self-regulate, gain awareness, increase control over their nervous system functioning and improve flexibility in physiological responding $[19,20]$. It has been found that biofeedback training induces relaxation, increases attention to task and reduce impulsivity [21]. Till date review of literature provides ample evidence regarding the effectiveness of alternative systems of medicine like CBT, RET, yogic techniques and music therapy in controlling aggressive behaviors. On the other hand biofeedback training specifically emerges as a very effective technique in developing selfcontrol over undesirable behaviors. But its efficacy has yet not been explored in enhancing self-esteem of people. Following the traditional viewpoint that low self-esteem causes aggression, and the therapeutic role of EMG biofeedback in improving the psychological health of people among diverse age groups, the present research was designed to analyze the effect of EMG biofeedback on self-esteem and reactive aggression among male adolescents.

\subsection{Hypotheses}

On the basis of review of literature, the following hypotheses were formulated:

1. EMG biofeedback would be effective in enhancing self-esteem and reducing reactive aggression of adolescents.

2. Post intervention scores of experimental group would be lower on reactive aggression and higher on self-esteem as compared to pre intervention scores.

\section{Method}

\subsection{Sample}

A total of 415 male subjects in the age range of 16 to 19 (Mean=17.21, $\mathrm{SD}=0.84$ ) years were selected randomly from various senior secondary schools of Patiala. They were assessed on Reactive-Proactive Aggression Questionnaire (RPAQ) and Self-Esteem Inventory (SEI) in a group setting. Individuals ( $\mathrm{n}=195)$ who scored higher on reactive aggression and lower on self-esteem were considered for the intervention program. However, 15 subjects were not willing to participate in the intervention program. All the screened in participants were randomly assigned to experimental $(n=90)$ and control groups $(n=90)$. 


\subsection{Tools Used}

\subsubsection{Reactive-Proactive Aggression Questionnaire (RPAQ) [22]}

It was used to measure the reactive aggression among adolescents for the study. It consists of 23 items which are distributed unequally among reactive aggression (11 items) and proactive aggression (12) items. The score for reactive and proactive aggression ranges from 0-22 and 0-24 respectively. In the present research, reactive aggression part of questionnaire was used where higher score represents high level of reactive aggression. The internal consistency (alpha) of the questionnaire is .84 , test-retest reliability is .81 and validity is .78 .

\subsubsection{Self-esteem Inventory (SEI) [23]}

It was used to measure self-esteem of the subjects. The short-form of the scale consists of 25 items. The score ranges from 0-100. Higher score indicates high self-esteem. The reliability coefficient of the inventory is 0.71 to 0.80 .

\subsubsection{Electromyograph (EMG) Biofeedback: "Biotrainer"}

EMG biofeedback, an electronic apparatus prepared by Medicaid systems, Chandigarh was used. This apparatus has LCD panel meter on which the ongoing EMG activity of the subject can be seen. The apparatus has both auditory\& visual modes. In auditory mode, machine produces sound. This sound becomes pleasant as relaxation progresses. In the present investigation, EMG biofeedback was operated on visual mode. Visual meter displays 17 light steps (green 11, yellow 1, red 5 steps). Feedback gain ranges from 1 to 10 . When the subject was able to glow all the green color bars at 10 then feedback gain was reduced and the subject was again asked to try for glowing more green color bars.

\section{Design and Procedure}

An experimental and control group assessment design was used. EMG biofeedback training was provided to the participants of experimental group. Before the intervention program, an informal session was conducted to establish rapport with participants. This session further proceeded with the general introduction of the purpose, procedure and benefits of intervention program. The subject under training was explained about the session in which his goal was to glow maximum number of green color bars through his mental powers. More number of glowing green color bars indicated higher level of relaxation and glowing red bars meant higher level of tension. To achieve the objective of glowing green color bars the subject was instructed to take deep breaths for 3 to 5 minutes. It was the adaptation period. This period was followed by autogenic training in which the subject was told to repeat autogenic phrases while as the same time receiving feedback from glowing bars. The subject was instructed to repeat autogenic phrases "I feel absolutely quite, my hands are heavy and warm and my ankles, my knees and my hips feel heavy and relaxed". The session was continued for 30 minutes. In the first and second session some of the subjects were able to glow 6 to 7 green bars in 30 minutes at 8 feedback gain. As the number of sessions increased, they completed the sequence of green bars 2 to 3 times at 2 feedback gain in the duration of 30 minutes. After the completion of the sessions, the subjects of experimental group were asked about their experiences and the perceptions regarding the therapy. They $(68 \%)$ reported that it was difficult for them to relax in the initial stage of the therapy. However, they found it good in the later stage as they were able to relax their muscles completely and hence felt great. Many of them (88\%) reported that after receiving biofeedback training they experienced less difficulty in forgiving others which had improved their peer group relationships. Some of them (42\%) said, "Now, they listen others carefully and calm down at their own will."

After a few training sessions on the apparatus the participants were able to alter their state of mind and relax quickly at will. In the present study 10 sessions were given to each participant of experimental group and procedure for EMG biofeedback training was same for all the sessions. Whereas participants of control group were not given EMG biofeedback training but the investigator had general discussion on issues like study habits, time management and interpersonal relationships. After the successful completion of intervention, the participants of both groups i.e. experimental and control group were again administered on reactive aggression questionnaire and self-esteem inventory and scoring was done following guidelines provided in manuals. Obtained scores were subjected to statistical analysis.

\section{Results}

In order to examine the effect of EMG biofeedback in improving self-esteem of aggressive adolescents, one way analysis of variance were carried out comparing pre-post scores of experimental and control group that are presented in Table 1 to Table 6.

F-values indicating no significant differences between experimental and control group on the scores of reactive aggression and self-esteem before intervention program are presented in Table 2. Further, analyses for both groups revealed significant effects of EMG biofeedback training on reactive aggression and self-esteem. Reactive aggression was significantly lower and self-esteem was significantly higher for participants who received EMG biofeedback training as compared to who did not receive biofeedback training (Table 4). Participants of experimental group demonstrated a significant reduction in reactive aggression and significant improvement in scores on self-esteem after receiving biofeedback training (Table 6).

Table 1. Means and Standard Deviations for Pre-intervention scores on Reactive aggression and Self-esteem.

\begin{tabular}{llll}
\hline \multirow{2}{*}{ Variables } & Experimental group & \multicolumn{2}{c}{ Control group } \\
\cline { 2 - 4 } & Means & SD & Means \\
\hline Reactive aggression & 18.02 & 2.32 & 17.80 \\
Self-esteem & 35.33 & 10.12 & 37.11 \\
\hline
\end{tabular}


Table 2. ANOVA Summary for Pre-scores (Experimental \& Control group) on Reactive Aggression and Self-Esteem.

\begin{tabular}{lllll}
\hline Variables & Source of Variation & Sum of Squares & df & Mean Square \\
\hline \multirow{3}{*}{ Reactive Aggression } & Between Group & 21.222 & 1 & 21.222 \\
& Within Groups & 1098.578 & 178 & 6.172 \\
& Total & 1125.800 & 179 & 142.222 \\
Self Esteem & Between Group & 142.222 & 1 & $3.438(\mathrm{~ns})$ \\
& Within Groups & 15624.889 & 178 & 87.780 \\
\hline
\end{tabular}

Table 3. Means and Standard Deviations of Experimental and Control group on Post intervention scores on Reactive aggression and Self-esteem.

\begin{tabular}{|c|c|c|c|c|}
\hline \multirow{3}{*}{ Variables } & \multicolumn{4}{|c|}{ Intervention } \\
\hline & \multicolumn{2}{|c|}{ Experimental group } & \multicolumn{2}{|c|}{ Control group } \\
\hline & Means & SD & Means & SD \\
\hline Reactive aggression & 15.21 & 2.63 & 17.53 & 2.08 \\
\hline Self-esteem & 43.55 & 11.24 & 38.57 & 10.12 \\
\hline
\end{tabular}

Table 4. ANOVA Summary for the Post intervention scores (Experimental \& Control group) of Reactive Aggression, Self-Esteem.

\begin{tabular}{|c|c|c|c|c|c|c|}
\hline Variables & Source of variation & Sum of squares & df & Mean square & F-ratio & Partial eta Squared \\
\hline \multirow{3}{*}{ Reactive aggression } & Between groups & 242.672 & 1 & 242.672 & & \\
\hline & Error & 1003.389 & 178 & 5.637 & $43.05 * *$ & 0.195 \\
\hline & Total & 1246.061 & 179 & & & \\
\hline \multirow{3}{*}{ Self-esteem } & Between groups & 1115.022 & 1 & 1115.022 & & \\
\hline & Error & 20376.178 & 178 & 114.473 & $9.74 * *$ & 0.052 \\
\hline & Total & 21491.200 & 179 & & & \\
\hline
\end{tabular}

Table 5. Means and Standard Deviations for Pre and Post intervention scores on Reactive Aggression and Self-Esteem of Experimental Group.

\begin{tabular}{|c|c|c|c|c|}
\hline \multirow{2}{*}{ Variables } & \multicolumn{2}{|c|}{ Pre- intervention Scores } & \multicolumn{2}{|c|}{ Post- intervention Scores } \\
\hline & Means & SD & Means & SD \\
\hline Reactive aggression & 18.02 & 2.33 & 15.21 & 2.63 \\
\hline Self-esteem & 35.33 & 10.13 & 43.56 & 11.24 \\
\hline
\end{tabular}

Table 6. ANOVA Summary for Pre and Post intervention Scores on scores of Reactive Aggression and Self-Esteem of Experimental Group.

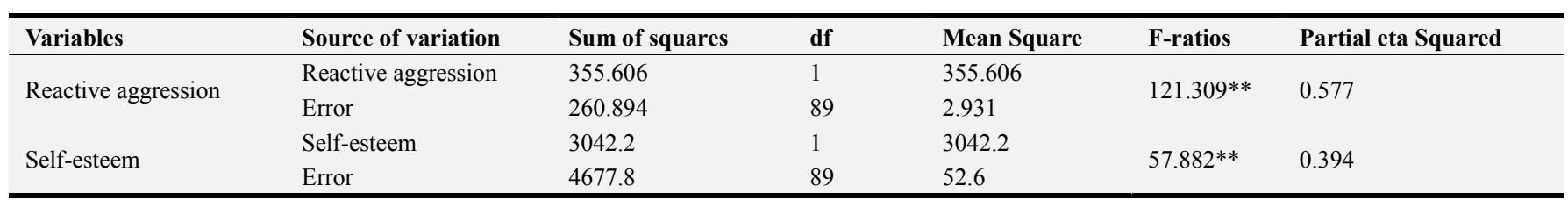

\section{Discussion}

The results of the present investigation supported the hypothesized effect of EMG biofeedback training on self-esteem and reactive aggression of male adolescents. This signifies that intervention program was beneficial for improving the behavior of participants. These findings are consistent with prior researches which have shown that biofeedback improves the self-image, increase attention to task and raises the level of confidence. It has been shown that the biofeedback training sessions were effective for enhancing self-regulation [24, 25], gaining awareness [19] and improving flexibility in physiological responding [21, 22]. Findings can also be explained on the basis of researches [26, $27,28]$ that have shown that self-esteem develops from cognitive process of evaluation of one's own self and the effective process of feeling one's worth in accomplishments and success in different areas of life. Individuals with low self-esteem evaluate themselves as unworthy and incompetent.
This has a profound influence on their emotions, cognitions and responses in the particular situation. However, as part of EMG biofeedback training the participants in experimental group were motivated to relax themselves and attain the goal of glowing more green bars. When the participants succeeded in attaining the goal, their perceptions of self as unworthy and incompetent started to change. Positive self-evaluation thus, had an influence on the participants' affect-state, thought and subsequent response. This successful modification in response patterns is a source of mastery experiences, which shows that a successful completion of task enhances the sense of self-efficacy [29] consequently promoting self-image of the individual. The repeated sessions of biofeedback may have stabilized the positive evaluation participants of experimental group. These beliefs or thoughts influence cognitive process, attitudes and behavior [30].

Support for the present findings can also be derived from Operant Conditioning model of learning [31, 32]. This model states that consequences play a significant role in modifying the occurrence of behavior [33]. It relies on the reinforcement 
of the signal displays. Participants in the present investigation were motivated to glow more green color bars by using autogenic and to observe the changes in their muscular activity on the LCD panel meter. This may have induced relaxation that leads reduction in electrical activity of frontal muscles. Increase in number of green bars served as the rewarding stimulus. This positive reinforcement could be the reason for modification in their behavior. In addition to this, the goal of biofeedback training is to make the users aware about their physiological functioning [34]. This enhances the meaningful monitoring of users own actions. This might help people with aggressive tendencies to focus on their behavior. Individuals with reactive aggression are described as hot headed and having high levels of arousal. This heightened arousal disrupts the individual's ability to process the information in a normal way [35]. As biofeedback induces and facilitates relaxation, this may have helped the participants of experimental group to consciously switch from sympathetic i.e. muscular tension to parasympathetic activities e.g. calmness. A significant reduction in scores of reactive aggression after biofeedback training sessions imply that EMG biofeedback training benefits to develop control over physiological responses and arousal producing stimuli.

\section{Conclusions}

Findings of the present study add to the existing literature that inaccurate perceptions can be altered and positive reinforcement determines the positive evaluation of one's own self. Biofeedback training not only improves the physiological functioning and performance but also enhances self-efficacy and transforms negative emotions into the experiences of self-mastery. Besides this, findings have significant implications in the area of counseling for adolescents. They can be aware about the significance of relaxed state of mind which may help them to enhance their academic functioning and deal effectively with unpleasant behaviors. Individuals with a tendency of aggression can be identified at the school level and can be provided with learning relaxation skills. Keeping in view the negative effects of aggression on psychosocial and academic life of adolescents, the findings can work as guidelines for counselors, teachers, parents and medical practitioners.

Despite the significant findings, some limitations of the study need to be addressed. Although efforts were made to provide enough time, ten sessions of the intervention may not be sufficient for maintaining alternations in cognitions for a longer period. Also, follow-up observations regarding the effects of training would have given important information. Besides self-reported measures, behavioral assessment rating scales from teachers and parents should have provided more knowledge regarding changes in the undesirable behaviors.

Compliance with Ethical Standards: There was no funding agency for the present study. Both of the authors have no conflicts of interest.

Ethical Concern: The present study was conducted on male adolescents. They were assured about confidentiality. Informed consent was obtained from all participants of the study.

\section{References}

[1] Schippell, P. (2001). The role of narcissism, self-esteem and attentional biases in childhood reactive and proactive aggression. (Electronic Thesis or Dissertation). Retrieved from https://etd.ohiolink.edu/

[2] Dodge, K. A., \& Coie, J. D. (1987). Social-information-processing factors in reactive and proactive aggression in children's peer groups. Journal of Personality and Social Psychology, 53 (6), 1146-1158. https://doi.org/10.1037/0022-3514.53.6.1146

[3] Harter, S. (1998). Development of self-representations. In W. diamond (Series Ed.) \& N.

[4] Rosenberg, M. (1986). Conceiving the self. Krieger: Malabar, FL.

[5] Sowislo, J. F., \& Orth, U. (2013). Does low self-esteem predict depression and anxiety? A meta-analysis of longitudinal studies. Psychological bulletin, 139, 213-240.

[6] Fairburn, C. G., Welch, S. L., Doll, H. A., Davies, B. A., \& O' Connor, M. E. (1987). Risk factors of bulimia nervosa: a community based case control study. Archives of general psychiatry, 54, 509-517.

[7] Donnellon, M. B., Trzesniewski, K. H., Robins, R., Moffitt, T. E., \& Caspi, A. (2005). Low self-esteem is related to aggression, antisocial behavior, and delinquency. Psychological science, $16,328-335$.

[8] Wilburn, V. R., \& Smith, D. E. (2005). Stress, self-esteem and suicidal ideation in late adolescents. Adolescents, 40 (157), 33-45.

[9] Ostrowsky, M. K. (2009). Are violent people more likely to have low self-esteem or high self-esteem? Aggression and Violent Behavior, 15, 69-75.

[10] Shaheen, F., \& Jahan, M. (2014). Role of Self Esteem in Development of Aggressive Behavior Among Adolescents. International Journal of Education and Psychological Research (IJEPR), 3 (4).

[11] Donellan, M. B., Trzesniewski, K., Robins, R., \& Moffitt, T. E. (2005). Low Self-Esteem Is Related to Aggression, Antisocial Behavior, and Delinquency. Psychological Science 16 (4): 328-335. DOI: 10.1111/j.0956-7976.2005.01535.x

[12] Muraven, M., \& Baumeister, R. F. (2000). Self-regulation and depletion of limited resources: Does self-control resemble a muscle? Psychological Bulletin, 126 (2), 247-259. https://doi.org/10.1037/0033-2909.126.2.247

[13] Baumeister, R. F., Smart, L. \& Boden, J. M. (1996). Relation of threatened egotism to violence and aggression: The dark side of self-esteem. Psychological Review, 103 (1), 5-33.

[14] Amad, S., Gray, N. S., \& Snowden, R. J. (2020). Self-esteem, narcissism, and aggression: different types of self-esteem predict different types of aggression. Journal of Interpersonal violence. https://doi.org/10.1177\%2F0886260520905540

[15] Smith, E. R., \& Mackie, D. M. (2008). Intergroup emotions. In M. Lewis, J. M. Haviland-Jones, \& L. F. Barrett (Eds.), Handbook of emotions (p. 428-439). The Guilford Press. 
[16] Papps, B. P., \& O’Carroll, R. E. (1998). Extremes of self esteem and narcissism and the experience and expression of anger and aggression. Aggressive Behavior, 24 (6), 421-438. https://doi.org/10.1002/(SICI)1098-2337(1998)24:6\%3C421:: AID-AB3\%3E3.0.CO;2-3

[17] Glick, R. M., \& Greeco, C. M. (2010). Biofeedback and primary care. Prim care, 37 (1), 91-103.

[18] Jantos, M. (2008). Vulvodynia: A psychophysiological profile based on electromyographic assessment. Applied Psychophysiology and Biofeedback, 33 (1).

[19] Burke, A. (2003). Biofeedback and the CAM consumer. Biofeedback Magazine, 31 (3), 13-15.

[20] Kessler, R., Soukup, J., Davis, R., Foster, D., Wilkey, S., Van Rompay, M., \& Eisenberg, D. (2001). The use of complementary and alternative therapies to treat anxiety and depression in the United States. American Journal of Psychiatry, 158 (20), 289-294.

[21] Omizo, M. M., \& Michael, W. B. (1982). Biofeedbackinduced relaxation training and impulsivity, attention to task and locus of control among hyperactive boys. Journal of learning disabilities, 15, 414-422.

[22] Raine, A., Dodge, K. A., Loeber, R., Gatzke-Kopp, L., Lynam, D., \& Reynolds, C. (2006). The Reactive-Proactive Aggression (RPQ) Questionnaire: Differential correlates of reactive and proactive aggression in adolescent boys. Aggressive Behavior, $32,159-171$.

[23] Coopersmith, S. (1981). Self-Esteem Inventories Manual. Redwood City, CA: Mind Garden Inc.

[24] Tanis, C. (2008). The effect of heart rhythm variability biofeedback with emotional regulation on the athletic performance of women collegiate volleyball players. (Doctoral dissertation, Capella University, Minnesota, United States). Retrieved from http://citeseerx.ist.psu.edu/viewdoc/download?doi=10.1.1.695 $.6609 \&$ rep $=$ rep $1 \&$ type $=$ pdf
[25] Kavussanu, M., Crews, D. J., \& Gill, D. L. (1998). The effect of single versus multiple measures of biofeedback on basketball free throw shooting performance. International journal of sport psychology, 29, 132-144.

[26] Huitt, W. (2011). A holistic view of education and schooling: Guiding students to develop capacities, acquire virtues, and provide service. Revision of paper presented at the $12^{\text {th }}$ Annual International Conference sponsored by the Athens Institute for Education and Research (ATINER), May 24-27, Athens, Greece. Retrieved from http://www.edpsycinteractive.org/papers/holistic-view-of-scho oling-rev.pdf

[27] Purkey, J. M. (1988). Self-concept and academic performance in Jamacian Teenagers. Journal of Social Psychology, 129 (5), 725-736.

[28] James, W. (1890). Principles of Psychology. New York: Holt.

[29] Bandura, A. (1997). Self-efficacy: the exercise of control. New York: Freeman.

[30] Omizo, M., Omizo, S., \& Kitaoka, S. (1998). Guided affected and cognitive imagery to enhance Self-esteem among Hawaiian Children. Journal of Multicultural Counseling and Development, 26 (1), 52-62.

[31] Skinner, B. F. (1938). The behavior of organism: an experimental analysis. New York: Appleton-century-crofts.

[32] Skinner, B. F. (1953). Science and human behavior. New York: Macmillan.

[33] Basmajian, J. B. (1989). Biofeedback: principle and practice for clinician, $3^{\text {rd }}$ Ed. Baltimore: Williams and Wilkins.

[34] Suinn, R. M. (1983). Imagery and sports. In Sheikh A. A (Ed): Imagery: Current Theory, Research, and Application. John Wiley \& Sons, 507-534.

[35] Tyson, P. D. (1998). Physiological arousal, reactive aggression, and the induction of an incompatible relaxation response. Aggression and Violent Behavior, 3 (2), 143-158. 